\title{
Life cycle of Corophium insidiosum (Crustacea, Amphipoda) in laboratory culture
}

\author{
K. K. C. NAIR ${ }^{1} \&$ K. Anger ${ }^{2}$ \\ ${ }^{1}$ National Institute of Oceanography, Regional Centre; \\ Cochin 682018, Kerala, India, \\ and \\ ${ }^{2}$ Biologische Anstalt Helgoland (Meeresstation); \\ D-2192 Helgoland, Federal Republic of Germany
}

\begin{abstract}
The life cycle of Corophium insidiosum (Crawford) was investigated for the first time in laboratory cultures. This amphipod is mainly a suspension feeder, but it can also switch to deposit feeding. It was cultivated in standing, unaerated finger bowls, feeding on detritus, living or dried algal matter, rotifers (Bracbionus plicatilis), or large-sized phytoplankton (e. g. the flagellate Scrippsiella faeroense). A mixture of these items gave best results and hence was used for long-term cultivation. Preliminary results are presented on ingestion rate (suspension feeding), digestion rate, starvation resistance, and elemental and biochemical composition. In the life cycle of C. insidiosum, several factors were found to play an important role: temperature, individual age, sex, and in contrast to other amphipod species thus far studied also the age of the mother animal at the time of breeding. Increasing temperature reduces the total life span, the age and size at the time of attaining sexual maturity, and the duration of marsupial development. It increases growth and moulting rate. At increasing individual age, the growth rate, and in males also the moulting rate, decrease, while the number of offspring per brood and surprisingly also the duration of its marsupial development increase. Females generally have a longer life span than males, and they show a higher number of moults, higher moulting frequency and growth rate, and a larger maximum body size. Body length and age at the time of reaching sexual maturity are smaller in males than in females. Furthermore the age of the mother animal at the time of breeding proved to be of particular importance: Individuals from early broods have an apparently longer life span than those originating from late broods, and they have more moults, mostly a higher growth rate, higher number of broods, higher total number of offspring, and, surprisingly, also a longer period of incubating their broods. These major factors have differing combined effects.
\end{abstract}

\section{INTRODUCTION}

Corophium insidiosum (Crawford) is widely distributed in the North Sea and Western Baltic Sea (Schellenberg, 1942). In shallow, brackish inshore areas and estuaries with a high degree of turbidity this amphipod species occurs frequently in extremely dense populations (Dahl, 1948; Muus, 1967; Schütz, 1969; Rasmussen, 1973; Maurer, 1977; Sheader, 1978). C. insidiosum has also been reported in particularly high numbers from organically polluted areas (Anger, 1975, 1977; Birklund, 1977).

Since it is presumed to have considerable local importance as a food item for inshore 
populations of shrimp and young fish, a first estimate of its production was made in an extensive field study by Birklund (1977). The first laboratory experiments (combined with field observations) were published by Sheader (1978), shortly after the present investigation had been finished.

The present paper reports on some observations on nutrition, starvation resistance, and chemical composition of C. insidiosum. The life cycle in laboratory cultures is described, and the influence of some important factors is discussed. Our findings supplement the results obtained by Birklund (1977) and Sheader (1978), whose work greatly increased the knowledge of this ecologically important amphipod species. It could be shown that cultivation of $C$. insidiosum is not difficult, and hence, it will be possible to obtain further data on the biology and ecology of this species.

\section{MATERIAL AND METHODS}

Living material was collected by divers, who scraped epifauna from the surface of jetties at Helgoland Harbour (North Sea) and transported it in bags. Individuals of Corophium insidiosum were sorted out in the laboratory under a dissecting microscope and maintained in finger bowls containing $100 \mathrm{ml}$ of filtered sea water. A laboratory population for additional observations was maintained in a closed system as described by. Nair et al. (1978). The salinity of the sea water used in all experiments varied in the range 29 to $33 \%$. The $\mathrm{pH}$ usually fluctuated between 7.8 and 8.4 .

In research cultivation (Kinne, 1977) and in experimental studies, knowledge of the nutritional requirements of the animal to be cultivated is of primary importance. The suitability of several food mixtures was compared in the following experiment: Male and female C. insidiosum were subdivided into three major size groups: adults $(3.9-4.8 \mathrm{~mm})$, medium-sized (3-4 mm), and juvenile $(0.9-1.9 \mathrm{~mm})$ animals. Depending on their availability, known numbers of each size group were introduced into separate glass bowls, each containing $300 \mathrm{ml}$ of filtered sea water. The experimental temperature was $10^{\circ} \mathrm{C} \pm 1{ }^{\circ} \mathrm{C}$. Four such sets were prepared and provided with different food combinations: (1) Brachionus plicatilis (rotifer) and natural detritus (1:1 by volume); (2) algal powder (dried and ground Ulva spec.), live thallus material (Ulva spec.), and yeast (1:1:1 by volume); (3) Scrippsiella faeroense (flagellate); (4) "mixed food" consisting of B. plicatilis (60\%), algal powder $(30 \%)$, detritus $(5 \%)$, and $S$. faeroense $(5 \%)$.

The rotifer $B$. plicatilis was cultivated in the laboratory on yeast suspension, and the flagellate $S$. faeroense in F/2 medium. The green alga Ulva spec. was collected in the rocky intertidal zone of the island of Helgoland, and partly used live, and partly freeze-dried and powdered. Before use as food, the algal powder was mixed with sea water, and after 2-3 days the scum which formed on top of the water was removed. Natural detritus was collected from the lower reaches of the intertidal zone and later dried at $60^{\circ} \mathrm{C}$ in an oven. The mixed food was always left overnight with aeration and light before using it.

In this experiment water and food were changed twice a week. The survival rate after a total period of 30 days served as an index of food value. According to this measure, the "mixed food" (no. 4, see above) gave best results, and hence was used as standard diet throughout the study. 
The preliminary experiments on food uptake of $C$. insidiosum were performed at $15^{\circ} \mathrm{C} \pm 1{ }^{\circ} \mathrm{C}$. To determine feeding rates, for each experiment 20 males and 20 females (all adults) were introduced into bottles filled with $250 \mathrm{ml}$ of filtered sea water. Small pieces of silicon tube served as artificial borrows for the animals. A known concentration of $B$. plicatilis was added, and at 6-h intervals the concentrations were determined again in experimental and control bottles. The average ingestion rates were calculated from the differences observed over a period of $24 \mathrm{~h}$.

Observations on the behaviour and life cycle of C. insidiosum were carried out by means of a dissecting microscope. An eye-piece micrometer was used for size measurements in live amphipods. Body size was measured as distance from the tip of the rostrum to the end of the telson.

The average time required between ingestion and defecation was estimated in a separate experiment: Another 40 adult $C$. insidiosum ( 3.5 to $4.5 \mathrm{~mm}$ body length) of both sexes were starved for $24 \mathrm{~h}$, and then placed individually in separate finger bowls containing sea water $\left(18^{\circ} \mathrm{C}\right)$ with mixed food (B. plicatilis and algal powder). Observations were made at 1-h intervals, and the time at which the first faecal pellet appeared was noted.

The ability of $C$. insidiosum to survive starvation was tested in relation to sex, age, and temperature. In each experiment, 10 animals were kept separately in finger bowls with Millipore-filtered sea water $(100 \mathrm{ml})$. The water was renewed every second day. Juveniles were used for these experiments shortly after release from the brood pouch. The temperatures in the experiments were kept constant at $10^{\circ}, 15^{\circ}$, and $20^{\circ} \mathrm{C}$ respectively. Mortality was noted daily.

The biochemical and elemental composition of C. insidiosum was determined in material freshly collected from the field in August 1978. Animals $<3 \mathrm{~mm}$ in total length and gravid females were excluded from the analyses. Wet weight was determined after blotting the amphipods for a few seconds on filter paper. Before freeze-drying the material in a GT 2 (Leybold-Heraeus) apparatus to constant weight, it was rinsed briefly in fresh water to remove adhering salt. Dry weight was measured at an Autobalance AD-2 (PerkinElmer). For biochemical analyses, the freeze-dried material was thoroughly homogenized and treated according to the standard methods described by Raymont et al. (1964). Each value given later represents an average of five readings.

Carbon, nitrogen, and hydrogen contents of juveniles and adult males and females were estimated by means of an Elemental Analyzer Model 1104 (Carlo Erba Science) using Cyclohexane-2, 4-Dinitrophenylhydrazone as a standard. Depending on the individual dry weight, 2 to 10 individuals were analyzed. Energy equivalents were calculated from carbon contents using the $\mathrm{N}$-corrected conversion factor of Salonen et al. (1976) and from biochemical composition using the factors given by Winberg (1971) and the nitrogen correction by Kersting (1972).

Studies on the life cycle of $C$. insidiosum, including observations on growth rate, moulting frequency, fecundity, mortality, and maximum life span were carried out in the laboratory under three different constant temperature regimes: $10^{\circ}, 15^{\circ}$, and $20^{\circ} \mathrm{C}$. The standard food mixture described above was given every second day after water change. No aeration was applied. All experiments were carried out under a $12: 12$-h photoperiod using artificial light from a $40-\mathrm{W}$ daylight neon lamp. The culture was started with juveniles obtained in the laboratory from 35 pairs of C. insidiosum which had been collected in the 
field. They were divided into three groups and exposed to the three experimental conditions. They were allowed to remain together (4 to 6 in each bowl) until their first moult. After this moult, the sexual differences were apparent (cf. Sheader, 1978). One male and one female were then kept in each bowl for further observation; in some exceptional cases more than one female was kept with a single male because the natural sex ratio caused a surplus of females. Later the broods produced successively by these animals were reared separately and studied experimentally as described above.

\section{RESULTS AND DISCUSSION}

\section{Tube building}

Juveniles freshly released from the brood pouch build small tubes within $24 \mathrm{~h}$ after they have been introduced into their experimental bowls. After a few days they often discard their tube and build a new one. Between the first and the second moult this behaviour was observed 3 to 4 times, but in later stages of its life, Corophium insidiosum becomes less ready to build new tubes.

The technique of tube building and the relationship between tube size and body size are virtually the same as recently described for the closely related species C. bonelli by Shillaker \& Moore (1978).

\section{Food uptake}

The four food mixtures described above did not cause significantly different mortality rates of Corophium insidiosum during a period of 30 days. Only if the flagellate Scrippsiella faeroense was given exclusively was survival less than with other diets. There is always some mortality of juveniles, but very little in medium-sized and adult individuals. The "mixed food" consisting of Brachionus plicatilis, algal powder, detritus, and phytoplanktion (see above) resulted in a particularly low mortality (only 2 juveniles) and hence was regarded as especially well suited for C. insidiosum; therefore it was used as standard diet in all later experiments.

According to these experiments and direct observations, C. insidiosum is an omnivorous particle feeder. It was never observed hunting prey, but normally suspension-feeding inside its tube by means of creating a current. This is done by rhythmic splashing of the pleopods transporting water to the rear. The antennae were observed directing particles actively into the tube. Small food particles are transported to the mouth by means of the first pair of gnathopods and maxillipedes. Large particles are reduced to smaller size by the second gnathopods or are thrown out with the water current. C. insidiosum is able to turn within the parchment-like tube to catch particles from the other end if there is no directed current. The juveniles feed in the same way as the adults, but mostly on ciliates and other minute particles.

The ingestion rate of adult C. insidiosum (at $15^{\circ} \mathrm{C}$ ) feeding on $B$. plicatilis has been determined in preliminary experiments: In one experiment water and food were renewed 
every $6 \mathrm{~h}$; the ingestion rate measured was 15 to 23 rotifers per amphipod $\mathrm{h}^{-1}$. In a parallel experiment the initial water and food were used for $24 \mathrm{~h}$; here, the ingestion rate decreased during the observation period to values of about 1 rotifer $h^{-1}$. Two explanations are possible for this decrease: (1) Water quality deteriorated due to waste products. (2) The decreasing prey concentration due to feeding by $C$. insidiosum caused a decreasing predation efficiency and consequently lower average predation rates toward the end of the experiment. After this preliminary observation, no final conclusions about the true causes can be drawn, but it seems certain that only a high frequency of water and food change ensures optimal nutrition by suspension-feeding alone. We presume that this amphipod species switches to deposit feeding when suspension-feeding is ineffective due to low prey density. The first explanation seems to be less likely, since C. insidiosum is well adapted to turbid water of rather bad quality.

C. insidiosum has been observed feeding on deposited particles such as detritus, protozoans, and diatoms (see also Dahl, 1973; Sheader, 1978), but mostly acting as a suspension-feeder. This behaviour was also described for C. bonelli by Enequist (1950).

Sheader (1978) observed a relationship between feeding activity and daylength. In our experiments this factor was kept constant, and no apparent variation in feeding activity was found.

\section{Digestion rate}

In order to determine the time needed to digest the food taken up by Coropbium insidiosum, the average time between the beginning of feeding on Brachionus plicatilis and algal powder (after starvation) and the first appearance of faecal pellets was measured at $18^{\circ} \mathrm{C}$. Defecation begins after 2 to $7 \mathrm{~h} ; 50 \%$ of all individuals were found to have defecated for the first time after $5 \mathrm{~h}$. Most of the animals that defecated at the end of this period were males. This observation suggests a possible faster digestion by females than by males.

\section{Starvation}

It is a well-known fact that metabolism increases with increasing temperature and hence, survival time during starvation is expected to be correlated inversely with temperature. Surprisingly, this pattern could not be distinctly observed in Corophium insidiosum. The maximal survival time of males and juveniles shows the expected trend: It decreases in both groups from about 20 days at $10^{\circ} \mathrm{C}$ to about 12 days at $15^{\circ}$ and $20^{\circ} \mathrm{C}$. Females behave in a contrary way: Their survival time increases from 35 days at $10^{\circ} \mathrm{C}$ to 53 days at $15^{\circ} \mathrm{C}$ and 56 days at $20^{\circ} \mathrm{C}$. The cause for this finding is not clear: perhaps there was some other (unknown) factor involved at $10^{\circ} \mathrm{C}$.

Another surprising fact is the significantly higher resistance to starvation of females as compared with males. This finding can be interpreted by higher lipid reserves of the females, which have to produce yolk mass for the eggs. The maximal survival time (56 days), however, is much shorter than found e.g. in Gammarus duebeni (Kinne, 1959). In this brackish water species, males can survive up to 101 days at $19^{\circ}$ to $20^{\circ} \mathrm{C}$. 


\section{Elemental and biochemical composition}

In order to gain some data on the organic reserves in C. insidiosum, analyses of elemental and biochemical composition were carried out. Analyses of carbon (C), nitrogen $(\mathrm{N})$, and hydrogen $(\mathrm{H})$ are summarized in Table 1, those of biochemical constituents in Table 2. The data in Table 1 explain to some degree the results of the starvation experiments: Females contain much more organic substance than males and juveniles. Their energy content remains apparently higher also when calculated per unit dry weight (mg) instead of per individual.

Freshly hatched juveniles have a very high water content, and the remaining dry substance contains only relatively little organic carbon. Their energy equivalent is consequently low. Thus, it is surprising that the survival of starved males is not significantly higher than that of juveniles.

Table 1

Corophium insidiosum: Body weight, water contents, elemental composition, and energy equivalents in juveniles and in adult males and females. Absolute values (per individual) and relative values $\left(\%\right.$ or $\left.\mathrm{J} \cdot \mathrm{mg}^{-1}\right)$

\begin{tabular}{|c|c|c|c|}
\hline Components & Juveniles & \multicolumn{2}{|c|}{ Adults } \\
\hline Wet weight $(\mu \mathrm{g})$ & 267 & 402 & 502 \\
\hline Dry weight $(\mu \mathrm{g})$ & 20 & 182 & 218 \\
\hline Water $(\%)$ & 92 & 55 & 57 \\
\hline$(\mu \mathrm{g})$ & 2.9 & 49.9 & 76.6 \\
\hline$(\%)$ & 14.4 & 27.3 & 35.2 \\
\hline$(\mu \mathrm{g})$ & 0.6 & 11.9 & 17.8 \\
\hline$(\%)$ & 3.1 & 6.5 & 8.2 \\
\hline$(\mu \mathrm{g})$ & 0.5 & 7.9 & 12.9 \\
\hline$(\%)$ & 2.4 & 4.3 & 5.9 \\
\hline $\mathrm{C} / \mathrm{N}$ & 4.6 & 4.2 & 4.3 \\
\hline Energy $\quad J \cdot$ ind $^{-1}$ & 0.07 & 1.56 & 2.64 \\
\hline equivalent $\mathrm{J} \cdot \mathrm{mg}^{-1}$ & 3.74 & 8.56 & 12.13 \\
\hline
\end{tabular}

Table 2

Corophium insidiosum: Dry weight, biochemical composition, and energy equivalents (including and excluding chitin) in adult individuals. Absolute values (per individual) and relative values $\left(\%\right.$ or $\left.\mathrm{J} \cdot \mathrm{mg}^{-1}\right)$

\begin{tabular}{|c|c|c|}
\hline Components & $\mu \mathrm{g} \cdot$ ind $^{-1} / \mathrm{J} \cdot$ ind $^{-1}$ & $\% / \mathrm{J} \cdot \mathrm{mg}^{-1}$ \\
\hline Dry weight & 240 & 100 \\
\hline Protein & 100.8 & 42.0 \\
\hline Carbohydrate & 9.1 & 3.8 \\
\hline Lipid & 30.7 & 12.8 \\
\hline Chitin & 48.5 & 20.2 \\
\hline Ash & 7.4 & 3.1 \\
\hline incl. & 4.15 & 17.30 \\
\hline equivalent & 3.37 & 14.04 \\
\hline
\end{tabular}


Biochemical analyses were only carried out with adult Corophium insidiosum (Table 2). Both composition and energy contents of this amphipod species correspond roughly to earlier data found in marine crustaceans (e.g. Raymont et al., 1971, and other papers cited therein; Dagg, 1976; Nair \& Anger, 1979) except copepods, which are generally much richer in lipids, carbon, and emergy. It is interesting that adult C. insidiosum are very similar in all parameters summarized in Tables 1 and 2 (including dry weight) to zoea-2 larvae of Hyas araneus (Anger \& Nair, 1979). Crustaceans of similar size, weight, and nutrition seemingly have similar body composition and energy contents.

\section{Sex ratio}

The sex ratio (males per females) determined in field populations off the island of Helgoland varied between 0.25 in August and 0.33 in December. A similar pattern was found by Sheader (1978) at the northeastern coast of England, but the range of variation (0.1 to 0.9) was higher than that of our observations. Anger (1975) found highest values in May (up to 0.67), and lowest values in September-October (down to 0.04) in populations of Kiel Bay (western Baltic Sea). The lowest values recorded by Rasmussen (1973) were about 0.1 .

Intersexes, as observed by Watkin (1941) in Corophium volutator and by Anger (1975) in $C$. insidiosum, were not evident in the Helgoland population. The laboratory cultures revealed a sex ratio of about 0.67 . The difference from the field population cannot be explained here. Possibly, females have a relatively high mortality when they are juveniles (before their sex can be recognized). In amphipods, besides genetic factors there are several external factors controlling sex: temperature and salinity, light, parasites, and others (for recent review see Bulnheim, 1978).

\section{Life span}

The following observation is probably the most important one of this study: Maximal life span of Corophium insidiosum varies not only with ecological factors such as temperature, but also with the age of the mother animal at the time of spawning.

After the completion of the first set of cultivation experiments, both males and females were found to fall mainly within two categories regarding life span, number of moults, and number of broods produced. After selecting juveniles from different broods produced by females at various stages of their life, the influence of the environmental temperature and of the "status of brood" (early or late) on the maximal life span of C. insidiosum were investigated separately.

The results can be seen in Table 5: Individuals produced in an early brood live longer than those developed from late broods; in both groups females normally live longer than males.

Increasing temperature reduces the life span of $C$. insidiosum; this influence is much stronger between $10^{\circ}$ and $15^{\circ} \mathrm{C}$ than between $15^{\circ}$ and $20^{\circ} \mathrm{C}$. The fact that the "status of brood" has an influence on an individuals's life cycle was observed for the first time. The generally longer life span in females has been described by Segerstråle (1940) and Muus (1967) for C. volutator. 


\section{Mortality}

The mortality pattern in a population of Corophium insidiosum is apparently independent of temperature, "status of brood", and sex: There is relatively high mortality (36 to $42 \%$ ) in juvenile stages (especially during the time of the first moult) and again in the last 2 to 4 weeks of the total life span of the generation under consideration. In the time between there is only very little mortality over an extended period.

Brood mortality (loss of eggs from the marsupium) as described by Sheader (1978) was not determined in this study. The number of offspring reported later in this paper was investigated only as number of juveniles actually hatched, not as total number of eggs laid.

\section{Growth and moulting rate}

Two measures of growth have been used in this study: Increase in total body length and in number of antennal segments. While the second antenna consistently had 6 segments in juveniles and adults of all sizes and in both sexes, the number of segments in the first pair of antennae increased with total body growth from 6 to 9 (in a few cases up to 10) in females, and from 6 to 11 in males. Thus, the number of antennal segments can be used as an additional index of growth (Tables 3 and 4). Males of the same body size usually have 1 to 2 segments more than females.

In Table 5 the most important data of Tables 3 and 4 are summarized. It is obvious that individuals produced in late broods not only have a shorter life span, but also fewer moults than animals from early broods. This is particularly striking in the females, which in general moult about twice as frequently as do the males.

Animals of both sexes mostly moulted approximately at the same time until they reached sexual maturity. After this time, males only moulted 1 to 3 times, but females at more or less regular intervals, which depended mainly on temperature. At $10^{\circ} \mathrm{C}$, moulting rate is so low compared with higher temperatures that in spite of a longer life span (see above), the number of moults does not increase, but decreases in females (Table 5).

Six females were isolated after reaching sexual maturity and kept separately at $20^{\circ} \mathrm{C}$ without males. Five of them were found to moult 10 times, and the 6 th one 8 times (in total). The counterparts which were left under the same temperature moulted 14 times. The total life span was in all cases about 144 days. This finding is in accordance with those of Kinne (1959), who observed in Gammarus duebeni that moulting intervals in females are prolonged when the animals are maintained without males.

The length increment per moult is usually higher in males than in females and in animals from late broods it is higher than in those from early broods. Maximum body size is similar in late and early broods, but there is a significant difference between males and females: The latter always become about 1.2 to 1.4 times larger than the former. Temperature had no clear influence on maximum body size in our experiments.

The daily length increment is significantly influenced by several factors: This measure for growth rate in the narrower sense shows an increasing trend with increasing temperature (especially from $10^{\circ}$ to $15^{\circ} \mathrm{C}$; cf. section "life span"). In females it is usually higher than in males. 
Table 3

Corophium insidiosum: Early brood. Growth (moulting stages, body length, antennal segments) and reproduction (brood size and duration of marsupial development) in laboratory culture. Mean values and standard deviations (in parentheses)

\begin{tabular}{|c|c|c|c|c|c|c|c|c|}
\hline \multirow{2}{*}{$\begin{array}{c}\text { Moult } \\
\text { No. } \\
-\end{array}$} & \multicolumn{2}{|c|}{$\begin{array}{l}\text { Time } \\
\text { (days) }\end{array}$} & \multicolumn{2}{|c|}{$\begin{array}{l}\text { Body length } \\
\text { (mm) }\end{array}$} & \multicolumn{2}{|c|}{$\begin{array}{l}\text { Antennal } \\
\text { segments }\end{array}$} & \multirow{2}{*}{$\begin{array}{c}\text { Juveniles } \\
\text { per female } \\
\text { - }\end{array}$} & \multirow{2}{*}{$\begin{array}{l}\text { Incubation } \\
\text { time (days) }\end{array}$} \\
\hline & $0^{2}$ & q & $\delta$ & $q$ & $\sigma$ & o & & \\
\hline \multicolumn{9}{|c|}{$10^{\circ} \mathrm{C}$} \\
\hline 1 & \multicolumn{2}{|c|}{$18(2)$} & \multicolumn{2}{|c|}{$1.5(0.2)$} & \multicolumn{2}{|c|}{6} & - & - \\
\hline 2 & $35(2)$ & $35(2)$ & $2.6(0.1)$ & $2.6(0.2)$ & 7 & 6 & - & - \\
\hline 3 & $64(3)$ & $64(3)$ & $3.3(0.2)$ & $3.5(0.2)$ & 8 & 7 & - & - \\
\hline 4 & $88(4)$ & $88(4)$ & $3.6(0.2)$ & $3.8(0.1)$ & 0 & 8 & - & - \\
\hline 5 & $136(3)$ & $99(2)$ & $4.1(0.2)$ & $4.0(0.2)$ & 10 & 8 & \multicolumn{2}{|c|}{ first oviposition } \\
\hline 6 & $167(3)$ & $118(2)$ & $4.2(0.1)$ & $4.4(0.2)$ & 11 & 8 & $10(1)$ & $10(3)$ \\
\hline 7. & - & $128(3)$ & - & $4.5(0.1)$ & - & 9 & $16(3)$ & $10(1)$ \\
\hline 8 & - & $145(2)$ & - & $5.0(0.1)$ & - & 9 & $16(2)$ & $17(3)$ \\
\hline 9 & - & $150(2)$ & - & $5.2(0.2)$ & - & 9 & - & - \\
\hline 10 & - & $189(3)$ & - & $5.4(0.1)$ & - & 9 & $4(1)$ & $16(4)$ \\
\hline 11 & - & $220(2)$ & - & $5.6(0.2)$ & - & 10 & - & - \\
\hline \multicolumn{9}{|c|}{$15^{\circ} \mathrm{C}$} \\
\hline 1 & \multicolumn{2}{|c|}{$7(2)$} & \multicolumn{2}{|c|}{$1.2(0.1)$} & \multicolumn{2}{|c|}{6} & - & - \\
\hline 2 & $21(3)$ & $21(2)$ & $2.1(0.1)$ & $2.2(0.2)$ & 7 & 6 & _- & $\ldots$ \\
\hline 3 & $30(3)$ & $30(2)$ & $2.9(0.3)$ & $3.0(0.4)$ & 8 & 7 & - & - \\
\hline 4 & $38(4)$ & $38(3)$ & $3.4(0.2)$ & $3.5(0.1)$ & 9 & 8 & - & - \\
\hline 5 & $79(5)$ & $52(6)$ & $3.7(0.3)$ & $3.7(0.3)$ & 10 & 8 & \multicolumn{2}{|c|}{ first oviposition } \\
\hline 6 & $19(2)$ & $64(2)$ & $4.2(0.1)$ & $4.0(0.3)$ & 11 & 8 & $5(2)$ & $5(1)$ \\
\hline 7 & - & $79(4)$ & - & $4.3(0.3)$ & - & 9 & $6(3)$ & $8(2)$ \\
\hline 8 & - & $88(5)$ & - & $4.4(0.1)$ & - & 9 & $10(2)$ & $\begin{array}{l}8(2) \\
9(3)\end{array}$ \\
\hline 9 & - & $97(4)$ & - & $4.6(0.2)$ & - & 9 & $12(3)$ & $9(2)$ \\
\hline 10 & - & $106(2)$ & - & $4.7(0.1)$ & - & 9 & $16(2)$ & $9(3)$ \\
\hline 11 & - & $119(3)$ & - & $5.1(0.2)$ & - & 9 & $28(3)$ & $9(2)$ \\
\hline 12 & - & $133(3)$ & - & $5.3(0.1)$ & - & 9 & $6(2)$ & $13(3)$ \\
\hline 13 & - & $140(-)$ & - & $5.6(-)$ & - & 10 & - & - \\
\hline \multicolumn{9}{|c|}{$20^{\circ} \mathrm{C}$} \\
\hline 1 & \multicolumn{2}{|c|}{$5(2)$} & \multicolumn{2}{|c|}{$1.3(0.2)$} & \multicolumn{2}{|c|}{6} & - & - \\
\hline 2 & $13(1)$ & $13(1)$ & $1.7(0.1)$ & $1.7(0.1)$ & 7 & 6 & - & - \\
\hline 3 & $23(2)$ & $23(2)$ & $2.6(0.1)$ & $2.6(0.1)$ & 8 & 7 & - & - \\
\hline 4 & $29(1)$ & $29(3)$ & $3.4(0.2)$ & $3.3(0.1)$ & 9 & 8 & \multicolumn{2}{|c|}{ first oviposition } \\
\hline 5 & $89(3)$ & $36(2)$ & $3.7(0.1)$ & $3.4(0.1)$ & 10 & 8 & $5(0.5)$ & $4(1)$ \\
\hline 6 & $118(2)$ & $52(3)$ & $4.2(0.2)$ & $3.5(0.1)$ & 11 & 8 & $6(2)$ & $6(2)$ \\
\hline 7 & - & $67(3)$ & - & $3.5(0.1)$ & - & 8 & - & - \\
\hline 8 & - & $73(2)$ & - & $3.6(0.2)$ & - & 8 & $8(3)$ & $6(1)$ \\
\hline 9 & - & $89(2)$ & - & $3.7(0.1)$ & - & 8 & $6(1)$ & $6(2)$ \\
\hline 10 & - & $100(2)$ & - & $4.0(0.2)$ & - & 9 & $16(3)$ & $10(2)$ \\
\hline 11 & - & $107(3)$ & - & $4.4(0.3)$ & - & 9 & $36(4)$ & $12(2)$ \\
\hline 12 & - & $118(3)$ & - & $5.0(0.2)$ & - & 9 & $6(3)$ & $12(2)$ \\
\hline 13 & - & $131(3)$ & - & $5.3(-)$ & - & 9 & - & - \\
\hline 14 & - & $142(2)$ & - & $5.4(-)$ & - & 9 & - & - \\
\hline
\end{tabular}

It is of course also dependent on the age of the animal: From the first to the 4th moult it is much higher than later (Tables 3 and 4). In Table 5, these data are compared directly. 
Table 4

Corophium insidiosum: Late brood. Growth and reproductive characters. (For explanation see Table 3)

\begin{tabular}{|c|c|c|c|c|c|c|c|c|}
\hline \multirow[t]{2}{*}{$\begin{array}{l}\text { Moult } \\
\text { No. }\end{array}$} & \multicolumn{2}{|c|}{$\begin{array}{l}\text { Time } \\
\text { (days) }\end{array}$} & \multicolumn{2}{|c|}{$\begin{array}{l}\text { Body length } \\
(\mathrm{mm})\end{array}$} & \multicolumn{2}{|c|}{$\begin{array}{l}\text { Antennal } \\
\text { segments }\end{array}$} & \multirow{2}{*}{$\begin{array}{c}\text { Juveniles } \\
\text { per female } \\
-\end{array}$} & \multirow{2}{*}{$\begin{array}{c}\text { Incubation } \\
\text { time (days) } \\
-\end{array}$} \\
\hline & $\sigma^{\circ}$ & q & 0 & 9 & $\sigma^{\circ}$ & $q$ & & \\
\hline \multicolumn{9}{|c|}{$10^{\circ} \mathrm{C}$} \\
\hline 1 & \multicolumn{2}{|c|}{$14(2)$} & \multicolumn{2}{|c|}{$1.7(0.3)$} & \multicolumn{2}{|c|}{6} & - & - \\
\hline 2 & $34(3)$ & $34(2)$ & $2.4(0.1)$ & $2.7(0.2)$ & 7 & 6 & - & - \\
\hline 3 & $47(2)$ & $47(3)$ & $3.4(0.2)$ & $3.4(0.1)$ & 8 & 7 & - & - \\
\hline 4 & $87(3)$ & $60(2)$ & $4.1(0.2)$ & $3.9(0.1)$ & 9 & 8 & $11(2)$ & $12(3)$ \\
\hline 5 & $119(2)$ & $82(4)$ & $4.4(0.2)$ & $4.4(0.2)$ & 10 & 8 & - & - \\
\hline 6 & $158(1)$ & $98(3)$ & $4.6(-)$ & $4.5(0.1)$ & 11 & 9 & $15(3)$ & $14(2)$ \\
\hline 7 & - & $142(2)$ & - & $5.3(0.2)$ & - & 9 & $16(1)$ & 14 (1) \\
\hline \multicolumn{9}{|c|}{$15^{\circ} \mathrm{C}$} \\
\hline 1 & \multicolumn{2}{|c|}{$9(2)$} & \multicolumn{2}{|c|}{$1.3(0.1)$} & \multicolumn{2}{|c|}{6} & - & - \\
\hline 2 & $30(2)$ & $30(3)$ & $2.8(0.3)$ & $2.7(0.2)$ & 7 & 7 & - & - \\
\hline 3 & $43(3)$ & $43(2)$ & $3.1(0.2)$ & $3.2(0.1)$ & 8 & 7 & - & - \\
\hline 4 & $69(2)$ & $54(3)$ & $3.5(0.1)$ & $3.5(0.1)$ & 9 & 8 & \multicolumn{2}{|c|}{ first 9 우 with eggs } \\
\hline 5 & - & $62(2)$ & - & $3.7(0.2)$ & - & 8 & $4(3)$ & $8(2)$ \\
\hline 6 & - & $69(3)$ & - & $3.8(0.2)$ & - & 8 & $8(2)$ & $7(3)$ \\
\hline 7 & - & $85(3)$ & - & $4.2(0.2)$ & - & 9 & $14(4)$ & $11(4)$ \\
\hline 8 & - & $98(2)$ & - & $4.4(0.2)$ & - & 9 & - & - \\
\hline \multicolumn{9}{|c|}{$20^{\circ} \mathrm{C}$} \\
\hline 1 & \multicolumn{2}{|c|}{$4(1)$} & \multicolumn{2}{|c|}{$1.2(0.1)$} & 7 & 6 & - & - \\
\hline 2 & $25(2)$ & $25(3)$ & $2.2(0.2)$ & $2.2(0.1)$ & 8 & 7 & - & - \\
\hline 3 & $33(1)$ & $33(3)$ & $2.8(0.3)$ & $3.0(0.1)$ & 9 & 8 & first $q q$ & with eggs \\
\hline 4 & $89(3)$ & $40(3)$ & $3.8(0.1)$ & $3.2(0.2)$ & 10 & 8 & $8(2)$ & $7(1)$ \\
\hline 5 & - & $61(2)$ & - & $4.5(0.4)$ & - & 9 & $10(3)$ & $7(2)$ \\
\hline 6 & - & $69(3)$ & - & $4.8(0.3)$ & - & 9 & - & - \\
\hline 7 & - & $79(2)$ & - & $5.1(0.2)$ & - & 9 & $16(4)$ & $10(2)$ \\
\hline 8 & - & $89(2)$ & - & $5.3(0.1)$ & - & 9 & - & - \\
\hline
\end{tabular}

Here the trends discussed above become visible again. Moreover, the complicated influence of the origin ("status of brood") becomes more obvious: In early-brood individuals, juvenile growth is more or less independent of sex, but highly dependent on temperature. When these animals become older, their growth rate becomes more dependent on sex: females grow twice as fast as males. In late-brood animals, the pattern is different. Here, females always grow much faster than males, and the temperature effect becomes even stronger in older than in younger individuals.

The growth rate of juveniles (until the 4 th moult) observed in our experiments is mostly larger than found by Birklund (1977) for very young stages in the field. This fact reveals very good growth conditions in our cultures. Direct comparison, however, is not possible, since there is no control of food, temperature, and other important factors in the field.

Sheader (1978) also described growth of Corophium insidiosum in a laboratory culture. His values for body size in relation to moult stage are much smaller than ours. 
Table 5

Corophium insidiosum: Survey of the most important life-cycle data in early- and late-brood individuals, and at different temperatures

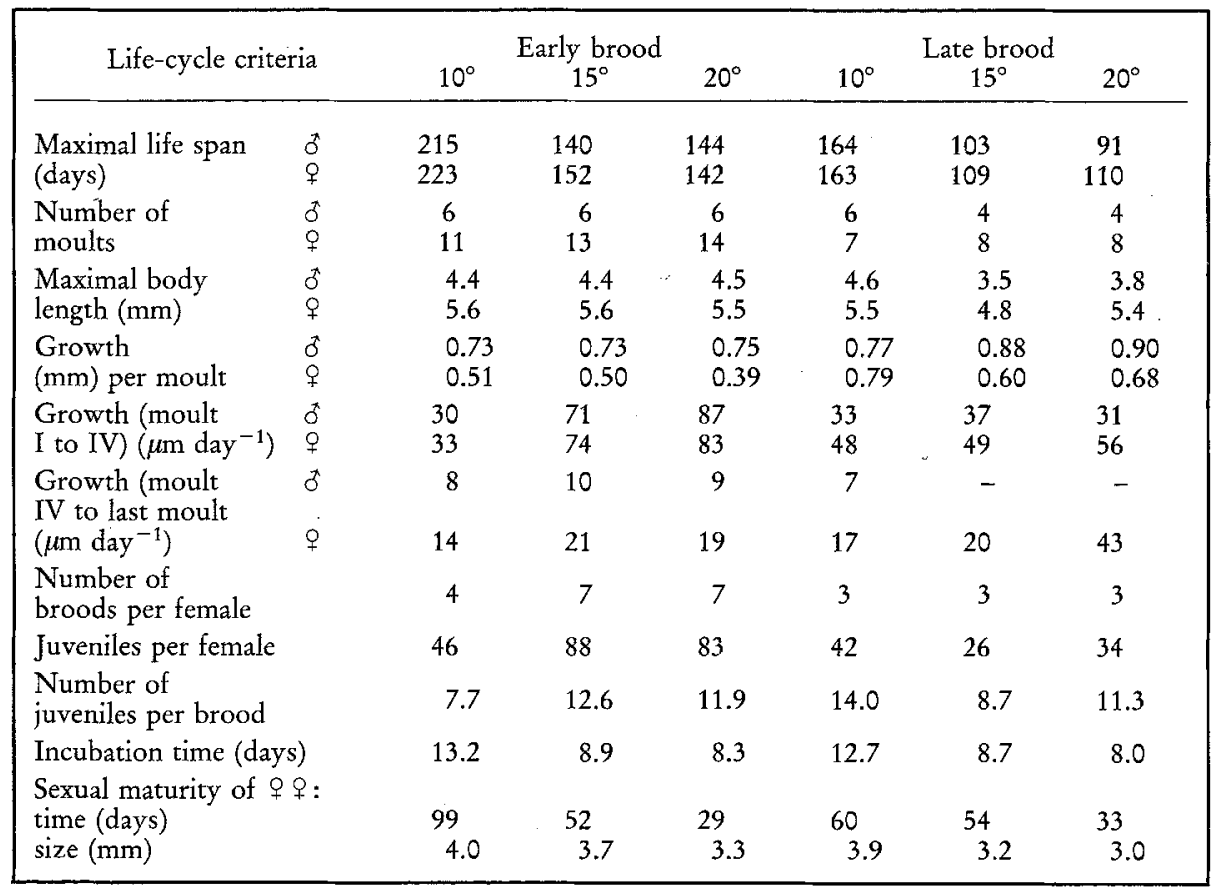

Unfortunately, he does not provide information on the temperature nor on the food used in his experiments. Thus, the causes for this high difference observed in growth rate per moult remain unknown.

\section{Attainment of sexual maturity}

The age at which sexual maturity is attained by Coropbium insidiosum is mainly determined by temperature (Tables 3 to 5): In females it takes about 1 month (after release from the brood pouch) at $20^{\circ} \mathrm{C}$, almost 2 months at $15^{\circ} \mathrm{C}$, and 2 to 3 months at $10^{\circ} \mathrm{C}$. Except in the case of $10^{\circ} \mathrm{C}$, no apparent differences between amphipods from early and late broods could be observed (Table 5).

In several additional experiments, males were found to reach sexual maturity prior to the females. The differences observed varied between 11 and 21 days.

The body size at which maturity is attained depends not only on temperature, but also on the "status of brood" (Table 5). At increasing temperature the effect of increasing growth rate cannot neutralize that of accelerated sexual maturation, and the amphipods become markedly smaller when they first reproduce. Individuals of late broods were found 
to be smaller than those of early broods when they reached maturity (Table 5), and males were usually smaller than females.

Depending on temperature, the females showed their first oviposition after the 4th to 5 th moult (early-brood), or 3rd to 4 th moult (late-brood animals) (Tables 3 and 4). The males were found able to fertilize them after one moult less.

In the Holbaek Fjord area (Denmark), C. insidiosum was observed to reach sexual maturity after about 25 days during the warmest period (early summer) in the field (Birklund, 1977). At much higher temperatures $\left(30-34^{\circ} \mathrm{C}\right.$ ) in the Mediterranean Sea, Casabianca (1975) found the same species reaching maturity within 8.5 to 20 days. The values found in our experiments represent typical temperature regimes of the North Sea and Baltic Sea regions from spring to autumn. Decreasing average body length at the time of first oviposition with increasing environmental temperature was also observed by Anger (1975), Birklund (1977), and Sheader (1978).

\section{Mating behaviour}

In Corophium insidiosum no precopulatory riding behaviour has been observed. After swimming around for a while, the female generally enters a tube occupied by a male. The two animals stay at the opposite ends of the tube with their uropods touching each other. Occasionally, they take a turn within the tube, gilding over each other. At intervals, the male presses its body for about 15 to $20 \mathrm{sec}$ against the female and then returns to its original position. This process is repeated several times, until the female moults 8 to $10 \mathrm{~h}$ later. After the moult, the male mounts transversely across the female, holding it with the antennae and bending its abdomen underneath it. In this way, the 7 th segment of the male comes into contact with the ventral side of the 5 th segment of the female, where the genital openings are located. Within 15 or $20 \mathrm{~min}$, copulation takes place 3 to 5 times. Thereafter, the male moves to one end of the tube, and 15 to $30 \mathrm{~min}$ later the eggs are laid. At the time of oviposition, a last copulation is carried out, perhaps ensuring that all eggs are fertilized. Sterile eggs were only seldom found. After mating is finished, the female drives away the male from the tube, and it remains alone until the juveniles are liberated.

\section{Incubation of eggs and hatching of juveniles}

The time between oviposition and hatching of juveniles (incubation period) is influenced not only by temperature (Table 5), but also to a high degree by the age of the female (Table 3 and 4) and a littly by the "status of brood" of the female (Table 5).

As expected, increasing temperature shortens the incubation period (average $Q_{10}$ between 10 and $20^{\circ} \mathrm{C}: 1.6$ ). The broods of older females take much longer to develop than those of younger ones, and early-brood females incubate their offspring longer than do the late-brood females. The latter influence, however, is much weaker than the former.

While temperature is known to influence physiological processes, it is less clear for the other factors. Differences in some important enzymes or in the biochemical composition of 
the eggs are possible explanations. Moreover the size of the early undeveloped eggs changes gradually: It increases from 0.3 to $0.42 \mathrm{~mm}$ diameter with increasing age of the mother animal. This fact, which was determined in additional cultivation experiments, certainly also contributes to a prolonged developmental time.

After hatching, the juveniles stay for another 8 to $10 \mathrm{~h}$ in the brood pouch, then they are released by the mother animal. About the same period of prolonged brood protection was also found by Sheader (1978). It is very short as compared to that in other amphipods, e. g. 5 days in Corophium volutator (Muus, 1967), 4 to 15 days in Gammarus duebeni (Kinne, 1959). The juveniles are never allowed to reenter the brood pouch. Their initial body length after liberation varied from 0.5 to $0.8 \mathrm{~mm}$, i. e. somewhat less than observed by Birklund (1977) in field samples and by Sheader (1978) in the laboratory.

Comparative values on the duration of marsupial development of C. insidiosum are given only by Sheader (1978). He observed an incubation period of 11 days at $15^{\circ} \mathrm{C}$ (i. e. about $25 \%$ longer than our findings), and 39 days at $5{ }^{\circ} \mathrm{C}$. The $Q_{10}$ value for this temperature range is 3.5 ; this is more than double the value between $10^{\circ}$ and $20^{\circ} \mathrm{C}$.

\section{Number of offspring per brood}

The number of eggs produced by a female in a single brood varied from 5 to 40 . Again, several factors were found responsible. Temperature has only little effect in late-brood females, but a considerable effect in animals from early broods (Tables 3 and 4). Generally, there is the trend that the maximum possible number of offspring (i. e. normally the last brood but one) increases with temperature.

The number of eggs produced in a single brood increases very much with the age of the mother animal. This increase can reach a factor of 7 (Table 3); its amount is enhanced by temperature increase, and it is more striking in females originating from early broods than in those from late broods (Tables 3 and 4 ). In the former group of females, which have more broods in their life than the latter group (Table 5), the last brood produced is again much smaller. There, the number of eggs is similar to that in the youngest reproducing stage. This trend had also been found in other amphipod species (e. g. Kinne, 1959, 1961).

Sheader (1978) observed an annual cycle of brood size in females of comparable size groups. Like Anger (1975), he found maximum numbers of eggs in May and declining values toward the end of the year. Variation increases with increasing size of the female.

\section{Number of broods}

Females originating from late broods usually reproduced 3 times in their life, independently of temperature (Table 5). Early-brood females revealed an apparent temperature dependence: At $10^{\circ} \mathrm{C}$ they produced 4 broods, at higher temperatures $\left(15^{\circ}\right.$ and $\left.20^{\circ} \mathrm{C}\right) 7$ broods. Hence, the total number of offspring is about the same in both groups at $10^{\circ} \mathrm{C}$, but is more than twice as much in the latter group at higher temperatures (Table 5).

Our findings on fecundity of Coropbium insidiosum reveal the principal ability of this species to produce many generations per year and thus a very high number of offspring. In 
the field, however, where food and temperature conditions are not optimal over the whole year, much smaller numbers were observed: Sheader (1978) found only 2 generations per year on the north-eastern coast of England, Anger (1975) found 3 generations in Kiel Bay (Western Baltic Sea), and Casabianca (1975) distinguished 5 to 6.5 generations near Corsica (Mediterranean Sea).

\section{CONCLUDING REMARKS}

The amphipod Corophium insidiosum has for the first time been cultivated repeatedly in the laboratory over its entire life cycle. It could be shown that this species does not demand a complicated cultivation technique nor any special food which is difficult to provide. Since C. insidiosum is adapted to turbid coastal and estuarine waters, no elaborate or sophisticated water-quality management is necessary. These opportunistic characteristics (cf. Anger, 1977) make the species a suitable laboratory animal for further studies on life cycle, physiology, ecology, and genetics, as well as for aquaculture purposes.

Several factors proved to have crucial roles in the life cycle of $C$. insidiosum: temperature, individual age, sex, and the age of the mother animal at the time of breeding. They have both single and combined effects on the total life span, growth and moulting rate, attainment of sexual maturity, marsupial development, egg number per brood, and total number of broods produced. However, several questions remain open after this first laboratory study on the whole life cycle of this species. Therefore, and for the above reasons, C. insidiosum is a promising subject for future studies in different fields of marine biology.

Some peculiarities found in C. insidiosum but not in other amphipod species should be of particular interest for such studies: The ability to utilize different food resources by switching from deposit feeding to suspension feeding and vice versa widens the ecological niche of $C$. insidiosum and thus makes it opportunistic. The study of niche width and resource partitioning in different communities should provide further information on the ecological role of $C$. insidiosum.

The mating behaviour is also very peculiar: The female searches the male and enters its tube; this finding is in contrast to the behaviour observed by Watkin (1941) in C. volutator and even more so to that known for other amphipod groups (e. g. Schellenberg, 1942). Further biological observations should be worthwhile.

The important role of the "status of brood" (origin from an early or late brood of the mother animal) in the life cycle was observed for the first time. It is not yet clear if this is only a unique finding in our material, a special characteristic in C. insidiosum, or a widely occurring pattern in amphipods. Further cultivation experiments are supposed to elucidate this enigma.

Acknowledgements.The first author is deeply indebted to Prof. O. Kinne, Director, Biologische Anstalt Helgoland (FRG) for providing working facilities at the Marine Biological Station Helgoland and also for the constant encouragement extended throughout the period of studies. He is grateful to Deutscher Akademischer Austauschdienst (DAAD) for financial support, and to Dr. S. Z. Qasim, Director, National Institute of Oceanography, (C. S. I. R.), Goa, (India) for his interest in this study and for allowing him to carry out this work on deputation. The authors wish to express their thanks to Dr. W. Greve and Dr. E. Hagmeier for supplying the original "seed" cultures of Brachionus plicatilis 
and Scrippsiella faeroense. Thanks are due to Dr. J. Markham for correcting the manuscript and to all staff members of the Marine Station at Helgoland who have helped and contributed to this work from time to time.

\section{LITERATURE CITED}

Anger, K., 1975. Benthos und Abwasser. Diss., Univ. Kiel, 327 pp.

- 1977. Benthic invertebrates as indicators of organic pollution in the western Baltic Sea. Int. Revue ges. Hydrobiol. 62, 245-254.

- \& Nair, K. K. C., 1979. Laboratory experiments on the larval development of Hyas araneus (Decapoda, Majidae). Helgoländer wiss. Meeresunters. 32, 36-54.

Birklund, J., 1977. Biomass, growth and production of the amphipod Corophium insidiosum Crawford, and preliminary notes on Corophium volutator (Pallas). Ophelia. 16, 187-203.

Bulnheim, H. P., 1978. Interaction between genetic, external and parasitic factors in sex determination of the crustacean amphipod Gammarus duebeni. Helgoländer wiss. Meeresunters. 31, 1-33.

Casabianca, M. L., 1975. Méthode de calcul de la production par estimation de la mortalité. C. r. hebd. Séanc. Acad. Sci., Paris 280, 1139-1142.

Dagg, M. J., 1076. Complete carbon and nitrogen budget for the carnivorous amphipod, Calliopius leaviusculus (Kröyer). Int. Revue ges. Hydrobiol. 61, 297-357.

Dahl, E., 1948. On the smaller Arthropoda of marine algae, especially in the polyhaline waters of the Swedish west coast. Diss. Lund., 193 pp. (Unders. över Oresund 35).

- 1973. Ecological range of Baltic and North Sea species. Oikos (Suppl.) 15, 85-90.

Enequist, P., 1950. Studies on the soft-bottom amphipods of the Skagerak. Zool. Bidr., Uppsala 28, $297-492$.

Kersting, K., 1972. A nitrogen correction for caloric values. Limnol. Oceanogr. 17, 643-644.

Kinne, O., 1959. Ecological data on the amphipod Gammarus duebeni. A monograph. Veröff. Inst. Meeresforsch. Bremerhaven 6, 177-202.

- 1961. Growth, moulting frequency, heart beat, number of eggs and incubation time in Gammarus zaddachi exposed to different environments. Crustaceana, 2, 26-35.

- 1977. Research cultivation. In: Marine ecology. Ed. by O. Kinne. Wiley-Interscience, Chichester 3 (2), 579-1293.

Maurer, D., 1977. Estuarine benthic invertebrates of Indian river and Rehoboth bays, Delaware. Int. Revue ges. Hydrobiol. 62, 591-629.

Muus, B. J., 1967. The fauna of Danish estuaries and lagoons. Meddr. Danm. Fisk.-og Havunders. 5, $1-316$.

Nair, K. K. C., Gopalakrishnan, I. C., George Peter, M. \& Rao, T. S. S., 1978. A closed sea water circulating system for the cultivation of marine and estuarine organisms in the laboratory. Indian J. mar. Sci. 7, 159-162.

- \& Anger, K., 1979. Experimental studies on the life cycle of Jassa falcata (Crustacea, Amphipoda) Helgoländer wiss. Meeresunters. 32 (In press).

Rasmussen, E., 1973. Systematics and ecology of the Isefjord marine fauna (Denmark). Ophelia 11, $1-495$.

Raymont, J. E. G., Austin, J. \& Linford, E., 1964. Biochemical studies on marine zooplankton. I. The biochemical composition of Neomysis integer . J. Cons. perm. int. Explor. Mer 28, 354-363.

- Srinivasagam, R. T. \& Raymont, J. K. B., 1971. Biochemical studies on marine zooplankton. IX. The biochemical composition of Euphausia superba. J. mar. biol. Ass. U. K. 51, 581-588.

Salonen, K., Sarvala, J., Hakala, I. \& Viljanen, M.-L., 1976. The relation of energy and organic carbon in aquatic invertebrates. Limnol. Oceanogr. 21, 724-730.

Schellenberg, A., 1942. Flohkrebse oder Amphipoden. Tierwelt Dtl. 40, 1-252.

Segerstråle, S. G., 1940. Zur Biologie des Amphipoden Corophium volutator, nebst Angaben über die Entwicklung und Rückbildung der Oostegitenborsten bei dieser Art. Comment. biol. Soc. sci. Fenn. 7, 1-40.

Sheader, M., 1978. Distribution and reproductive biology of Coropbium insidiosum (Amphipoda) on the north-east coast of England. J. mar. biol. Ass. U. K. 58, 585-596. 
Shillaker, R. O. \& Moore, P. G., 1978. Tube building by the amphipods Lembos websteri Bate and Coropbium bonnellii Milne Edwards. J. exp. mar. Biol. Ecol. 33, 169-185.

Schütz, L., 1969. OOkologische Untersuchungen über die Benthosfauna im Nordostseekanal III. Autökologie der vagilen und hemisessilen Arten im Bewuchs der Pfähle: Makrofauna. Int. Rev. ges. Hydrobiol. 54, 553-592.

Watkin, E. E., 1941. The yearly life cycle of the amphipod Corophium volutator. J. Anim. Ecol. 10, 77-93.

Winberg, G. G. (Ed.), 1971. Methods for the estimation of production of aquatic animals. Acad. Press, London, $175 \mathrm{pp}$. 